\title{
Cooperative Structure-Directing Effects in the Synthesis of a High-Silica Zeolite Mazzite Analogue
}

\author{
Qi Shi", Jinyang Yu, Zhengwei Song, Xiaozhen Kang
}

Research Institute of Special Chemicals, Taiyuan University of Technology, Taiyuan, China.

Email: ${ }^{*}$ shiqi594@163.com

Received February $29^{\text {th }}, 2012$; revised March $31^{\text {st }}, 2012$; accepted April $28^{\text {th }}, 2012$

\begin{abstract}
A zeolite Mazzite (MAZ) analogue with high silica content has been synthesized from a $\mathrm{Na}_{2} \mathrm{O}-\mathrm{Al}_{2} \mathrm{O}_{3}-\mathrm{SiO}_{2}$-morpholine$\mathrm{H}_{2} \mathrm{O}$ system. The crystal morphology of this MAZ analogue was found to consist of spherical agglomerates of diameter up to $17 \mu \mathrm{m}$. It has been unequivocally demonstrated that zeolite Mordenite (MOR) or amorphous material was produced instead in the absence of either morpholine or $\mathrm{Na}^{+}$. Associated phases indicate that the MAZ may be a "intermediate phase" between the crystallization fields of zeolites Analcime (ANA) and MOR. Thus, the zeolite MAZ analogue is seemingly derived from the cooperative structure-directing effect of the organic molecule morpholine and the inorganic cation $\mathrm{Na}^{+}$. The results of CHN elemental analyses as well as of thermogravimetric (TG) analyses confirmed that morpholine had been incorporated into the zeolitic structure.
\end{abstract}

Keywords: Crystal Growth; Sol-Gel Preparation; Characterization Methods; Mazzite Analogue

\section{Introduction}

Several types of zeolites with the MAZ framework are known, such as the naturally occurring zeolite Mazzite [1] and the synthetic aluminosilicate zeolites Omega [1], LZ-202 [2], and ZSM-4 [3]. This zeolite framework has 12 -membered ring pore, and has attracted a lot of research interest owing to its strong Brønsted acidity and its activity as a catalyst for alkylation [4], cracking [5], and isomerization [6]. The synthetic analogue of Mazzite is usually crystallized by using the tetramethylammonium cation as a structure-directing agent, and other organic molecules, such as pyrrolidine [4], piperazine [7], glycerol [8], and p-dioxane [9] can also be used as templating agents.

The use of organic molecules as structure-directing agents (SDAs) in the assembly of high-silica zeolites has attracted much attention in the past 30 years. Since the majority of readily available amines and derivatives thereof have been examined as SDAs, recent advances in high-silica zeolite synthesis have centered on synthesizing novel SDAs by more sophisticated routes or by employing more exotic SDAs [10]. However, from a practical perspective, the SDA should be commercially available or at least relatively easy to prepare. Morpholine was selected due to its low cost and ready availability, and because it has been generally used as a SDA to synthesize aluminophosphate molecular sieves with the CHA

*Corresponding author. framework, such as ZYT-6 [11] and AlPO4-34 [12]. However, reports of aluminosilica zeolite synthesis from morpholine are relatively rare. Using a combination of fluoride anion and morpholine, our research group has recently prepared the high-silica clathrate compound MTN by vapor-phase method [13] as well as by solvothermal method.

In the work described herein, we have examined the structure-directing effect of morpholine in the hydrothermal method combining inorganic cations or fluoride anion. This work has shown that by exploiting the cooperative structure-directing effects of the inorganic cation $\mathrm{Na}^{+}$and the organic molecule morpholine, a zeolite MAZ analogue can be successfully synthesized.

\section{Experimental Procedure}

The reagents used were morpholine $\left(\mathrm{C}_{4} \mathrm{H}_{9} \mathrm{NO},>98.5\right.$ wt $\%$ ), sodium hydroxide ( $\mathrm{NaOH},>99.0 \mathrm{wt} \%$ ), silica sol $\left(\mathrm{SiO}_{2}, 30 \mathrm{wt} \%\right)$, and aluminum hydroxide $\left(\mathrm{Al}(\mathrm{OH})_{3},>98\right.$ $\mathrm{wt} \%)$. Distilled water and sodium aluminate were prepared in our laboratory. A typical sample was prepared from a gel as follows: sodium hydroxide solution (3.16 $\mathrm{mL}, 10.6 \mathrm{~mol} \mathrm{NaOH} / \mathrm{L})$, sodium aluminate $(1.06 \mathrm{~mL}$, $\left.2.62 \mathrm{~mol} \mathrm{Al}_{2} \mathrm{O}_{3} / \mathrm{L}\right)$, and deionized water $(6.6 \mathrm{~mL})$ were thoroughly mixed in a beaker by stirring at room temperature for $60 \mathrm{~min}$. Morpholine $(1.94 \mathrm{~g})$ and silica sol $(9.18 \mathrm{~mL})$ were then added. After further stirring for about $10 \mathrm{~min}$, the mixture, with a molar ratio of $8.0 \mathrm{Na}_{2} \mathrm{O}$ : 
$1.0 \mathrm{Al}_{2} \mathrm{O}_{3}: 20.0 \mathrm{SiO}_{2}: 8.0$ morpholine: $400 \mathrm{H}_{2} \mathrm{O}$ was transferred to a stainless-steel autoclave and kept statically at $150^{\circ} \mathrm{C}$ in an oven for 5 days. The crystallinity, phase purity, and identity of the obtained samples were determined by X-ray diffractometry (XRD) (Rigaku, D/max 2500). The crystal morphology and size were observed by scanning electron microscopy (SEM) (JEOL, JSM35C). Thermogravimetric (TG) analysis (Netzsch, STA409) was carried out in air at a heating rate of $10^{\circ} \mathrm{C} / \mathrm{min}$ using $\gamma$-alumina as the reference. CHN analysis was carried out on an Elementar Vario EL analyzer.

\section{Results and Discussion}

First, we employed morpholine as a large SDA, together with inorganic cations $\left(\mathrm{Li}^{+}, \mathrm{Na}^{+}, \mathrm{K}^{+}\right)$or $\mathrm{F}^{-}$as co-SDAs. Interestingly, it was found that only $\mathrm{Na}^{+}$induced the formation of high-silica zeolite MAZ, whereas the other ions yielded only the clathrate compound MTN or amorphous material. The effects of the different combinations of morpholine and $\mathrm{Na}^{+}$on MAZ synthesis are listed in Table 1.

The morpholine $/ \mathrm{Al}_{2} \mathrm{O}_{3}$ ratio was varied from 0 to 8.0. According to the data in Table 1, in the absence of morpholine (Run 1) or with only a small amount added (Run 2), zeolite phase MOR was obtained. Zeolite MAZ was formed when the morpholine $/ \mathrm{Al}_{2} \mathrm{O}_{3}$ ratio was in the range 5.0 - 8.0 (Runs 3, 4). Thus, morpholine clearly served as a powerful structure-directing agent in the MAZ synthesis. The $\mathrm{Na}_{2} \mathrm{O} / \mathrm{Al}_{2} \mathrm{O}_{3}$ ratio was varied from 0 to 10.0. According to the data in Table $\mathbf{1}$, in the absence of $\mathrm{Na}_{2} \mathrm{O}$ (Run 5), only amorphous material was obtained. Zeolite MAZ analogue was formed when the $\mathrm{Na}_{2} \mathrm{O}$ / $\mathrm{Al}_{2} \mathrm{O}_{3}$ ratio was in the range $6.0-8.0$ (Runs 3,7). At $\mathrm{Na}_{2} \mathrm{O} / \mathrm{Al}_{2} \mathrm{O}_{3}=3.0$ (Run 6), zeolite MOR was synthesized, while at $\mathrm{Na}_{2} \mathrm{O} / \mathrm{Al}_{2} \mathrm{O}_{3}$ ratios greater than 10.0 (Run 8) a mixture of zeolite MAZ and ANA was formed. The results showed that zeolite MAZ may be a "intermediate phase" crystallizing in the overlapping crystallization fields of MOR and ANA and also proved that $\mathrm{Na}^{+}$plays a structure-directing role in the formation of zeolite MAZ. Morpholine and $\mathrm{Na}^{+}$are necessary components of the gel and the absence of either one leads to the disappearance of the zeolite MAZ analogue from the crystallized products, implying that both are needed for the simultaneous stabilization of several different substructures in the gel that combine to yield the MAZ framework.

The situation here is consistent with previous arguments [14] concerning cooperative structure-directing effects in high-silica zeolites by using a combination of bulky and small structure-directing agents. Organization of the tetrahedral $\mathrm{TO}_{4}$ units by the large morpholine molecules may not be energetically favorable, leading to the formation of amorphous materials. However, the presence of small $\mathrm{Na}^{+}$ions in the synthesis gel could improve the crystallization process by helping to overcome the energetic barrier of the nucleation. At the same time, $\mathrm{Na}^{+}$influences the types of secondary building units that form in the gel, leading to the formation of ANA and MOR. However, with the addition of morpholine, these small inorganic entities can gradually be assembled around the morpholine, thus opening up the possibility for the crystallization of another zeolite, i.e. MAZ. The synthesis data have shown that $\mathrm{Na}^{+}$and morpholine may together exert a cooperative structure-directing effect on MAZ synthesis.

The XRD pattern of typical MAZ (Table 1, Run 4) is shown in Figure 1. Comparison with the data reported in the literature [15] showed that the positions and relative intensities of the diffraction peaks were the same as that of zeolite MAZ, proving that the synthesized samples were a pure phase of the zeolite MAZ.

Analysis of the MAZ sample (Table 1, Run 4) revealed $\mathrm{C}, \mathrm{H}$ and $\mathrm{N}$ contents of $3.10,1.83$, and $0.86 \mathrm{wt} \%$, respectively, corresponding to a $\mathrm{C}: \mathrm{H}: \mathrm{N}$ molar ratio of 4.20:29.79:1.00. The $\mathrm{C} / \mathrm{N}$ ratio of the sample was close to that in morpholine, $\mathrm{C} / \mathrm{N}=4.0$, suggesting that morpholine

Table 1. The effects of morpholine and $\mathrm{Na}_{2} \mathrm{O}$ on MAZ synthesis. ${ }^{\mathrm{a}}$

\begin{tabular}{ccc}
\hline Run & Reactant composition (starting molar ratio) & Phase \\
\hline 1 & $8.0 \mathrm{Na}_{2} \mathrm{O}: 1.0 \mathrm{Al}_{2} \mathrm{O}_{3}: 20.0 \mathrm{SiO}_{2}: 0$ morpholine: $400 \mathrm{H}_{2} \mathrm{O}$ & $\mathrm{MOR}$ \\
2 & $8.0 \mathrm{Na}_{2} \mathrm{O}: 1.0 \mathrm{Al}_{2} \mathrm{O}_{3}: 20.0 \mathrm{SiO}_{2}: 3.0$ morpholine: $400 \mathrm{H}_{2} \mathrm{O}$ & $\mathrm{MOR}$ \\
3 & $8.0 \mathrm{Na}_{2} \mathrm{O}: 1.0 \mathrm{Al}_{2} \mathrm{O}_{3}: 20.0 \mathrm{SiO}_{2}: 5.0$ morpholine: $400 \mathrm{H}_{2} \mathrm{O}$ & $\mathrm{MAZ}$ \\
4 & $8.0 \mathrm{Na}_{2} \mathrm{O}: 1.0 \mathrm{Al}_{2} \mathrm{O}_{3}: 20.0 \mathrm{SiO}_{2}: 8.0$ morpholine: $400 \mathrm{H}_{2} \mathrm{O}$ & $\mathrm{MAZ}$ \\
5 & $0 \mathrm{Na}_{2} \mathrm{O}: 1.0 \mathrm{Al}_{2} \mathrm{O}_{3}: 20.0 \mathrm{SiO}_{2}: 8.0$ morpholine: $400 \mathrm{H}_{2} \mathrm{O}$ & Amorphous \\
6 & $3.0 \mathrm{Na}_{2} \mathrm{O}: 1.0 \mathrm{Al}_{2} \mathrm{O}_{3}: 20.0 \mathrm{SiO}_{2}: 8.0$ morpholine: $400 \mathrm{H}_{2} \mathrm{O}$ & $\mathrm{MOR}$ \\
7 & $6.0 \mathrm{Na}_{2} \mathrm{O}: 1.0 \mathrm{Al}_{2} \mathrm{O}_{3}: 20.0 \mathrm{SiO}_{2}: 8.0$ morpholine: $400 \mathrm{H}_{2} \mathrm{O}$ & $\mathrm{MAZ}$ \\
8 & $10.0 \mathrm{Na}_{2} \mathrm{O}: 1.0 \mathrm{Al}_{2} \mathrm{O}_{3}: 20.0 \mathrm{SiO}_{2}: 8.0$ morpholine: $400 \mathrm{H}_{2} \mathrm{O}$ & $\mathrm{MAZ}+\mathrm{ANA}$ \\
\hline
\end{tabular}

a: reaction temperature $150^{\circ} \mathrm{C}$, reaction time 5 days. 


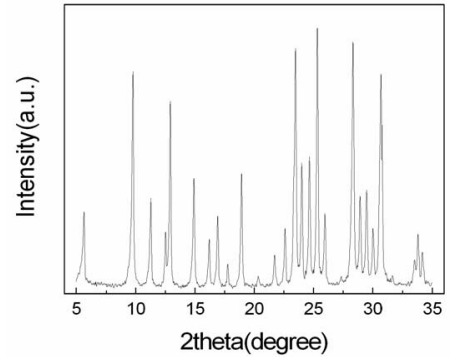

Figure 1. XRD pattern of typical MAZ sample.

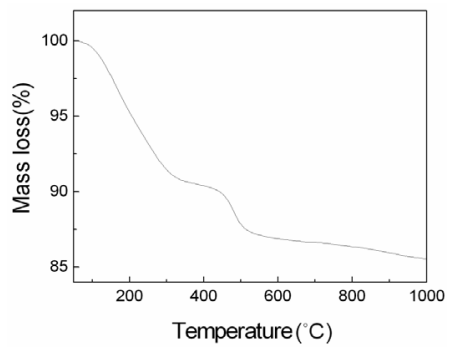

Figure 2. TG curve of typical MAZ sample.

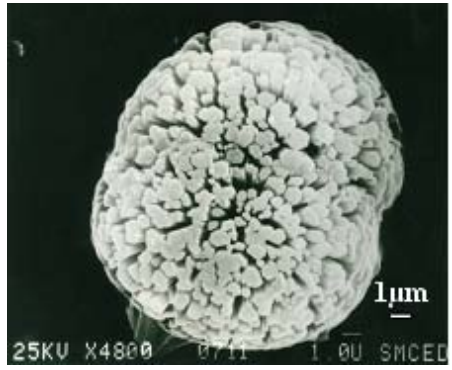

Figure 3. SEM image of typical MAZ sample.

were occluded in the micropores of the MAZ. However, the $\mathrm{H} / \mathrm{N}$ ratio of the sample, 29.79, was greater than that in morpholine, $\mathrm{H} / \mathrm{N}=9$. This deviation of the hydrogen content of the sample from that of morpholine can be explained in terms of the contribution of water molecules. Further calculation showed the content of morpholine to be about $5.6 \mathrm{wt} \%$ (based on C: $3.10 \mathrm{wt} \%$ ). As shown in Figure 2, the TG curve of MAZ (Table 1, Run 4) features two distinct main steps, the first between 50 and $300^{\circ} \mathrm{C}$ (8.5 $\mathrm{wt} \%)$, corresponding to the removal of water molecules, and the second between 300 and $1000^{\circ} \mathrm{C}(5.9 \mathrm{wt} \%)$, corresponding to the removal of the occluded structuredirecting species morpholine. The latter weight loss is in close agreement with the morpholine content estimated by $\mathrm{CHN}$ analysis $(5.6 \mathrm{wt} \%)$. The $\mathrm{TG}$ curve $\left(300^{\circ} \mathrm{C}\right.$ and $1000^{\circ} \mathrm{C}$ ) indicated that the guest molecules could not be fully released before the framework collapsed.

SEM image of the crystals of MAZ (Table 1, Run 4) is illustrated in Figure 3. It can be seen that the zeolite MAZ obtained with morpholine as the template consisted of spherical agglomerates up to $17 \mu \mathrm{m}$ in diameter com- prised of hexaprism crystals. The crystal growth and assembled procedure are being studied.

\section{Conclusion}

We have reported herein our recent studies on the crystallization behavior of the $\mathrm{Na}_{2} \mathrm{OAl}_{2} \mathrm{O}_{3} \mathrm{SiO}_{2}$ morpholine $\mathrm{H}_{2} \mathrm{O}$ system for zeolite MAZ synthesis. The obtained zeolite MAZ analogue grows as agglomerates of intergrown hexaprism crystals. It has been found that $\mathrm{Na}^{+}$ itself can lead to the specific zeolite structures MOR or ANA, but that the addition of the organic structure-directing agent morpholine to the gel can lead to the crystallization of MAZ. The experimental data have proved that the small cation $\mathrm{Na}^{+}$and the bulky molecule morpholine exert a cooperative structure-directing effect, resulting in the formation of the MAZ analogue. The results of CHN and TG analyses suggest that morpholine is occluded in the micropores of the MAZ analogue.

\section{REFERENCES}

[1] E. Galli, "Mazzite, A Zeolite," Crystal Structure Communications, Vol. 3, No. 2, 1974, pp. 339-344.

[2] D. W. Breck and G. W. Skeels, "Silicon Substituted Zeolite Compositions and Process for Preparing Same," US Patent No. 4503023, 1985.

[3] M. K. Rubin, C. J. Plank and E. J. Rosinski, "Synthesis of Zeolite ZSM-4," US Patent No. 4021447, 1977.

[4] E. M. Flanigen and E. R. Kellberg, "Synthetic Crystalline Zeolite and Process for Preparing Same," US Patent No. 4241036, 1980.

[5] A. J. Perrotta, C. Kirby, B. R. Mitchell and E. R. Tucci, "The Synthesis, Characterization, and Catalytic Activity of Omega and ZSM-4 Zeolites," Journal of Catalysis, Vol. 55, No. 2, 1978, pp. 240-249. doi:10.1016/0021-9517(78)90210-5

[6] V. Solinas, R. Monaci, B. Marongiu and L. Forni, "Isomerisation of 1-Methylnaphthalene over $\Omega$-Zeolite," $\mathrm{Ap}$ plied Catalysis, Vol. 5, No. 2, 1983, pp. 171-177. doi:10.1016/0166-9834(83)80130-4

[7] H. Xu, P. Dong, L. Liu, J. G. Wang, F. Deng and J. X. Dong, "Synthesis and Characterization of Zeolite MAZ in $\mathrm{Na}_{2} \mathrm{O}-\mathrm{Al}_{2} \mathrm{O}_{3}-\mathrm{SiO}_{2}-$ Piperazine- $\mathrm{H}_{2} \mathrm{O}$," Journal of Porous Materials, Vol. 14, No. 1, 2007, pp. 97-101. doi:10.1007/s10934-006-9013-2

[8] S. Yang and N. P. Evmiridis, "Synthesis of Omega Zeolite Without Use of Tetramethylammonium(TMA) Ions," Studies in Surface Science and Catalysis, Vol. 84, 1994, pp. 155-162. doi:10.1016/S0167-2991(08)64109-9

[9] B. De Witte, J. Patarin, J. L. Guth and T. Cholley, "Synthesis of Mazzite-Type Zeolites in the Presence of Organic Solvents: Study of the Structure Directing Role of p-Dioxane," Microporous Materials, Vol. 10, No. 4-6, 1997, pp. 247-257. doi:10.1016/S0927-6513(97)00013-8

[10] A. Burton and S. Elomari, "SSZ-60: A New Large-Pore 
Zeolite Related to ZSM-23," Chemical Communications, No. 22, 2004, pp. 2618-2619. doi:10.1039/b410010g

[11] M. Ito, Y. Shimoyama, Y. Saito, Y. Tsurita and M. Otake, "Structure of an Aluminosilicophosphate," Acta Crystallographica, Vol. 41, No. 12, 1985, pp. 1698-1700.

[12] L. Marchese, A. Frache, E. Gianotti, G. Martra, M. Causa and S. Coluccia, "ALPO-34 and SAPO-34 Synthesized by Using Morpholine as Templating Agent," Microporous and Mesoporous Materials, Vol. 30, No. 1, 1999, pp. 145-153. doi:10.1016/S1387-1811(99)00023-2

[13] J. X. Dong, X. Q. Tong, J. Y. Yu, H. Xu, L. Liu and J. P. $\mathrm{Li}$, "Synthesis of Large Single Crystals of a Clathrate
Compound MTN (a Zeolite-Like Material) by the Vapor-Phase Method," Materials Letters, Vol. 62, No. 1, 2008, pp. 4-6. doi:10.1016/j.matlet.2007.04.058

[14] A. B. Pinar, R. García, M. Arranz and J. Pérez-Pariente, "Co-Directing Role of Template Mixtures in Zeolite Synthesis," Studies in Surface Science and Catalysis, Vol. 170, 2007, pp. 383-388. doi:10.1016/S0167-2991(07)80864-0

[15] M. M. J. Treacy and J. B. Higgins, "Collection of Simulated XRD Powder Patterns for Zeolites," 5th Edition, Elsevier, Amsterdam, 2007. 